Cuadernos de Ilustración y Romanticismo

Revista Digital del Grupo de Estudios del Siglo XVIII

Universidad de Cádiz / ISSN: 2173-0687

nº 25 (2019)

\title{
ENTRE BURLAS Y VERAS: LAS ESTRATEGIAS REIVINDICATIVAS DE MANUELA TOMASA SÁNCHEZ DE OREJA Y FRANCISCA DE OSORIO, ESCRITORAS DE ALMANAQUES
}

María Dolores Gimeno Puyol

(Universitat Rovira i Virgili)

Recibido: 29-03-2019 / Revisado: 07-10-2019

Aceptado: 03-06-2019 / Publicado: 20-12-2019

Resumen: El género de los almanaques o pronósticos astrológicos, tan en boga en España en el siglo XVIII, fue también cultivado por mujeres, entre las cuales Manuela Sánchez de Oreja, la Gran Piscatora Aureliense, y Francisca de Osorio, la Musaraña del Pindo. Ambas aprovecharon la ocasión de escribir para plantear la reivindicación de las capacidades femeninas y de su derecho a publicar igual que los hombres, algo habitual entre las escritoras de entonces. Dado que las dos se adscribieron al modelo literario conformado por Torres Villarroel, utilizaron sus motivos temáticos y recursos estilísticos burlescos con ese fin, dotándolos de una nueva funcionalidad y en combinación con afirmaciones serias. De este modo participaron en el debate de los sexos del Dieciocho ya en los años 40 y 50, anticipándose a otras escritoras de finales de siglo.

Palabras Clave: Pronósticos astrológicos, mujeres, estilo burlesco, Manuela Sánchez de Oreja, Francisca de Osorio, escritura, siglo XVIII.

\section{BETWEEN JOKES AND TRUTHS: STRATEGIES FOR RECOGNITION BY MANUELA TOMASA SÁNCHEZ DE OREJA AND FRANCISCA DE OSORIO, WOMEN ALMANAC WRITERS}

AвsTRACT: The genre of almanacs or astrological forecasts, so in vogue in Spain in the 18th century, was also cultivated by women, such as Manuela Sánchez de Oreja, «la Gran Piscatora Aureliense», and Francisca de Osorio, «la Musaraña del Pindo». As was usual among the women writers of that time, they used their texts to argue in favour of female abilities and their equal right to publish their work as men did. Since both followed the literary model formed by Torres Villarroel, they used similar thematic motifs and burlesque style, while giving them new functionality and adding to them more serious affirmations related to their position as women writers. Thus, they participated in the gender debate of their time, anticipating already in the 40s and 50s other women writers later in the century.

KEYwords: Astrological forecasts, women, burlesque resources, Manuela Sánchez de Oreja, Francisca de Osorio, writing, $18^{\text {th }}$ century. 
Durante el siglo ilustrado, que tantos cambios socioculturales promovió en toda Europa, se incrementó el número de mujeres que trataron de salir del ámbito doméstico a través de la actividad literaria. Sus nombres se han ido rescatado con el auge de los estudios llamados de género, se han editado textos aún manuscritos o se han reeditado y estudiado otros poco conocidos. Las españolas fueron en su mayoría autoras de poemas, de obras teatrales o de tema religioso y hubo bastantes traductoras de obras ajenas, aunque practicaron todas las tipologías textuales. ${ }^{\mathrm{I} 2}{ }^{2}$

No resulta extraño que algunas probasen fortuna con los almanaques o pronósticos astrológicos, un éxito de ventas entre las capas populares que atrajo a quienes deseaban obtener ganancias económicas o un lugar en la República de las Letras, o ambas cosas. Así, en medio de tantos almanaqueros del Dieciocho español, hallamos tres escritoras, una exigua pero lógica proporción: Manuela Tomasa Sánchez de Oreja, la Gran Piscatora Aureliense, que publicó en la década de los 40 un pronóstico o almanaque y un Juicio sobre el cometa de 1744; ${ }^{3}$ Francisca de Osorio, la Musaraña del Pindo, de quien se conservan tres almanaques seriados como Pronóstico burlesco para I756, I757 y I758;4 y Teresa González, la Pensadora del Cielo, ya en los 70, de quien conocemos El estado del cielo para el año de I778, arreglado al meridiano de Madrid..., su segundo "piscator» que remite a otro anterior, aún sin localizar. ${ }^{5}$ Entre todas suman siete obras, con más de una en cada caso, un indicio de que no fueron incursiones aisladas, sino que albergaron el propósito de convertirse en escritoras. No obstante, como sucede con la mayoría de los autores de almanaques, tenemos pocos datos sobre su identidad, reducidos a los que ellas mismas aportan en las portadas: básicamente nombre, procedencia o lugar de residencia y, a veces, profesión; o a la imagen autobiográfica que exhiben, convertidas en protagonistas de los preámbulos literarios a sus pronósticos, siguiendo las pautas establecidas por Torres Villarroel, el Gran Piscator de Salamanca, innovador del género en España. ${ }^{6}$

Sea como fuere, con nombre de mujer, las tres aprovecharon la ocasión para intervenir en un nuevo debate de los sexos, que en el siglo ilustrado hispano había iniciado Feijoo con su famosa «Defensa de las mujeres» en I726. Pero solamente las dos primeras se presentaban como seguidoras del salamantino, $y$, por ende, de su nuevo modelo de almanaque, que acabó por imponerse. Manuela Tomasa Sánchez de Oreja, cuyo seudónimo la

I El presente trabajo se inscribe en el Proyecto de Investigación Almanaques literarios y pronósticos astrológicos en España durante el siglo XVIII: estudio, edición y crítica, del Plan Estatal de Investigación Científica y Técnica y de Innovación, Referencia: FFI2017-82179-P.

${ }_{2}$ García Garrosa (2007: 206) eleva a doscientas el número de escritoras españolas en el siglo xviır. Palacios Fernández (20I2), actualizando trabajos anteriores, suma 47 autoras de «Textos literarios» —incluidas ahí las traductoras-, una relación que se incrementa con algunas recopilaciones conjuntas poéticas o teatrales. BIESES ha digitalizado diversos paratextos de 37 escritoras de la centuria, dentro de un proyecto de estudio de las redes sociales de diversas autoras desde el xv al xviı que, para este último siglo, prevé alcanzar un total de 50.

3 El pronóstico para I742 ha sido editado íntegro en fechas recientes por Durán López (2013: 4I3-437) con una introducción y notas. El posterior sobre el cometa, por su rareza y brevedad, lo edito al final de este análisis a partir del ejemplar de la Biblioteca de Castilla-La Mancha (CCPB), que no contiene datos editoriales; existe otro en la British Library (Aguilar Piñal, I98I-200r: t. viı, 505).

${ }_{4}$ Para clarificar las referencias, hay que notar que la fecha del primer pronóstico está ausente del pie de imprenta, aunque se deduce su publicación el mismo año de 1756 , y que los otros dos aparecieron a finales del año anterior al que pronosticaban, es decir, en 1756 y en I757, respectivamente. Escribió después, en I759 y I760, sendos poemas laudatorios a Carlos III (Serrano Sanz, I975, t. II, p. 93).

5 Serrano Sanz (I975: t. I, 468-469) consigna tres pronósticos de la autora: para I773, I777 y I778, con la denegación del segundo. Aguilar Piñal solo indica datos de publicación del último; del de 1777 indica el expediente de aprobación en AHN, Consejos, 5538/7 con informe de Benito Bails, pero "No se concedió la licencia», y conjetura del primero: «Al parecer ya se publicó otro similar en I773 con el nombre de «La Pensadora del cielo». (I98I-20or: t. IV, 274).

6 Véase el exhaustivo estudio de Durán López (2015), que caracteriza «La creación del Gran Piscator de Salamanca» (2015: 45-48), así como los modelos previos, básico y extendido, y las distintas formalizaciones del heterogéneo corpus después de Torres Villarroel. 
Gran Piscatora Aureliense calcaba el del maestro, le dedica el suyo para subsanar el olvido de quienes se llamaban sus discípulos, subrayando su diferencia femenina: «Y que haya de ser una dama la que pague por ellos tan justa deuda! ¡Rara cosa!» (Sánchez de Oreja, [I742]: s. p.), y en su introducción literaria, lo llama «el mecenas de esta obra [...] ese resucitador glorioso de esta ciencia» ([1742]: Io); es más, en el posterior Juicio y pronóstico del cometa lo tilda de corresponsal asiduo: «mi siempre fiel y apasionado correspondiente» (Sánchez de Oreja, [1744]: s. p.). Francisca de Osorio, que le dedicó el de 1756, lo compara con el divino Platón y lo identifica con «Júpiter allá en los Cielos» (Osorio, [1756]: s. p.), e incluso luego, en su introducción al juicio del año, confiesa estar escribiendo el Elogio de Torres. 7

El modelo torresiano implicaba, además, la adopción de un registro burlesco en dos sentidos: que el narrador piscator protagonizaba un juego en esa parte previa y que las predicciones judiciarias —anuales o diarias-, siempre vigiladas por la censura, fuesen claramente festivas. Así, ese marco estructural lo utilizaron las tres piscatoras para plantear el debate de los sexos, un elemento que, ausente en los almanaqueros masculinos, seguía lo practicado por otras escritoras de la época, que aprovechaban la ocasión de publicar, y en especial los paratextos, en ese sentido. ${ }^{8}$ Pero solamente las dos seguidoras declaradas de Torres hicieron uso de sus estrategias burlescas, que fueron entreverando con afirmaciones serias. En ambas se centrará este análisis, por tratar de ver cómo dotan de una nueva funcionalidad reivindicativa a algunos motivos temáticos y recursos retóricos habituales en el género, y cómo realizan con ello su defensa de las capacidades de la mujer y, de ahí, de su derecho a publicar.

La mera elección de los pronósticos astrológicos para irrumpir en el panorama editorial era ya una muestra de esa capacidad y preparación, pues requería unos conocimientos matemáticos determinados, además de las aptitudes literarias y del conocimiento de su poética. En eso eran superiores a su sexo y también a la media masculina. Sin embargo, por ser un género menor, consumido por el pueblo y desdeñado por algunos doctos, muchos de los autores de almanaques miraban de elevarse declarando en sus portadas su condición de profesores de Matemáticas. A estos recelos literarios, las autoras sumaban los relacionados con su incursión en el panorama editorial, privativo masculino, sabedoras de las críticas que suscitarían (Álvarez Barrientos, 2006: 53); de ahí que realicen una exhibición explícita y añadida de cultura. Manuela Tomasa Sánchez de Oreja, aparte de natural y residente en el paraje toledano de Oreja — como informa su firma y el gentilicio aureliense de su seudónimo-, también se declara profesora de Matemáticas. Y esparce en su «Introducción» evidencias de su amplia cultura: una cita en latín del «príncipe de la Filosofía», Santo Tomás de Aquino, y una sátira dialogada de Luciano de Samosata sobre el vuelo planetario de Ícaro; es decir, filosofía y literatura clásica, que tuvo que aprender de forma autodidacta, igual que las Matemáticas, «que con genial inclinación practico, sin deber a profesor alguno de ellas más explicación, que la que bebí en la fuente de mi biblioteca» (Sánchez de Oreja, [1742]: I). En su segundo texto se presenta sin el seudónimo y, extrañamente, con Nicolasa como único nombre, quizás el tercero de los suyos de pila, o bien un apelativo o un juego onomástico; aunque la narradora confiesa

7 Teresa González, que publicó tras la prohibición de I767 de las predicciones judiciarias y ya fallecido Torres, no lo menciona y usa un registro grave, acorde a su seudónimo, y convierte su prólogo en una extensa apología de las mujeres. No incluye poemas para glosar las predicciones en los Cómputos del año, reducidas a datos científicos, con escuetas indicaciones sobre cosechas y salud.

8 López Cordón (2006: 210) lo subraya en relación con las anotaciones y prólogos de las traductoras, que exhibían ahí su saber además de reclamar un lugar en la República de las Letras. 
ser la autora de ambos y ahora se exhibe como personaje en su entorno cotidiano, en una casa cuya terraza dispone de un observatorio astronómico donde sostiene una "tertulia».

En cuanto a Francisca de Osorio Guzmán, residente en Santa Cruz de la Zarza, también en Toledo, cuando escribió el primero de 1756, y natural de la corte según los pronósticos de 1757 y I $75^{8}$, demuestra una vasta cultura. Abundan las alusiones a filósofos, políticos y referentes mitológicos grecorromanos y, según confiesa en su tercer «Juicio del año», había leído la Eneida, Ovidio y Juvenal y sabía griego; y además de la Astrología, era «naturalista» y tenía conocimientos de francés, italiano, Lógica y Metafísica, seguidora de Aristóteles (Osorio, I757: 9-10). Se adivina que adquirió esos conocimientos por su cuenta.

Si la exhibición de saber de una y otra resultaba lógica y necesaria para cargar de razón su incursión en la República de las Letras, encauzar su discurso dentro de un género consolidado, con la insistencia en la autoridad del maestro Torres, les proporcionaba un marco conocido por los lectores que las iban a juzgar. Sus dedicatorias a él, aval añadido, adoptaban las convenciones sin resabios burlescos, y como elemento diferencial vinculaban la captatio benevolentiae de rigor al tópico de la limitación femenina, además de apelar a la cortesía masculina para dispensar sus faltas. ${ }^{9}$ Plantean, pues, ya de entrada, de forma implícita, la antítesis hombre-mujer, aceptando la inferioridad bajo la capa de la falsa modestia, pero una vez fuera del espacio de la dedicatoria, retomarán esa oposición para cuestionarla. Constituye un argumento central en sus prólogos, que preceden las respectivas introducciones literarias, donde el diálogo hipotético que entablan con los lectores se presenta en términos de debate para desmentir cualquier limitación femenina.

En el «Prólogo» de su almanaque Manuela Tomasa Sánchez de Oreja se dirige a sus lectores comunes o letrados. Los invoca en parejas de opuestos, «hembras, o machos» la primera, y después otras según cualidades, concordadas en masculino: «tontos o discretos, simples, o compuestos, salados, o insípidos, bestias o bastos, cuerdos o locos» (Sánchez de Oreja, [r742]: s. p.). La enumeración deja ver cierto tono jocoso, que se hace airado para pedir una crítica sin anteojos misóginos e invocar su derecho a publicar: «que muerdan, tiren tarascadas, ladren, gruñan y hagan su oficio (que razón tienen, si los cuesta el dinero) mas que no distingan de sexos, que por más que se emperren y enfurezcan, se ha de pasear mi pronóstico (a pesar suyo) por donde quieran llevarle» (Sánchez de Oreja, [1742]: s. p.). El motivo de quien puede criticar porque paga, habitual en el género, se desprende aquí de ironía y pide una crítica restringida al mero texto, cuya conversión en materia publicada se reclama. Una vez esgrimido ese motivo, el prólogo concluye con una airada imprecación a los legos en la materia, a quienes la Gran Piscatora Aureliense desautoriza con una serie de gráficos descalificativos:

A los forasteros en esta ciencia, que solo parece que viven, para roer cosas ajenas, a ciegas, y sin luz, como el vil gusanillo de la carcoma, intimo (de parte de la señora Urania, a quien jamás han saludado) que luego luego que vean mi obra, no dejen de aguzar para ella sus dientes; pero advirtiendo que este animalejo se alimenta de madera, y siendo ellos unos zoquetes, no temo sus estragos, pues solo resultarán contra sus mismas entrañas. A Dios, amigos (Sánchez de Oreja, [I742]: s. p.).

9 Después de su primer pronóstico a Torres, Francisca de Osorio dedica los otros dos al Duque de Arcos —el de 1757 en prosa con tres octavas finales y el de 1758 un extenso romance-, y no presenta ahí ninguna reivindicación femenina. 
Se presenta, pues, frente a ellos, como preparada portavoz de Urania, la musa de la Astrología. Antes se ha dirigido a sus colegas para reclamarles el derecho a compartir el espacio literario, pero con ellos el tono es jocoso: «mi pronóstico [...] irá muy gustoso riéndose de todos: ¿Qué querían Vms. mentir a diestro, y a siniestro, con tantas barbas como unos zamarros, y dejarnos a las lampiñas sin una sed de este sabroso licor? Pues no, señores míos, mintamos a coros, y démonos por buenos» (Sánchez de Oreja, [1742]: s. p.). Usa ahí el motivo de las mentiras judiciarias, tan repetido por todos los almanaqueros, y recurre de nuevo a la antítesis entre ellos, aludidos con una sinécdoque y una comparación grotescas, y las delicadas «lampiñas», lo que alberga una sátira amable.

Si en el prólogo formula reclamaciones, firmes o festivas, en la «Introducción» literaria que sigue la Gran Piscatora de Oreja, convertida en personaje, se retrata como astróloga acreditada, y lo hace frente a sus colegas masculinos, a quienes presenta como astrólogos rutinarios que tratan de averiguar la colocación de los planetas «valiéndose de efemérides perpetuas» (Sánchez de Oreja, [1742]: 10) que no entienden y mienten en sus juicios, mientras que ella lo ve claro, aunque prefiere omitirlo. Podría pensarse que ironiza sobre sí misma, tan mentirosa como ellos, pero enseguida Venus entona su elogio y, tras advertirle de la envidia que sufrirá como el maestro Torres, la sitúa como la primera de sus alumnos en superlativo absoluto:

¡O tú, la más dichosa piscatora de estos tiempos, cuando tal alta ciencia suele ser infeliz desdoro de sus profesores! Júzgate, y con razón, merecedora de los mayores aplausos; pues logras en premio de tus astrológicos trabajos, y astronómicas tareas, que planetas y signos vengan conformes a manifestarte con evidencia lo que por conjeturas tantos desean inquirir, y tan pocos lo consiguen. Tú sola, por este medio, harás tu fama eterna, pregonando al orbe el eco de tu cavado bronce este favor, jamás logrado de otro alumno nuestro (Sánchez de Oreja, [1742]: Ir).

El ambiente es elevado en un escenario mitológico: una fantasía de signos que forman un nuevo zodiaco, «aladas tropas de ninfas» (Sánchez de Oreja, [1742]: 9) que dialogan con unos coros, planetas que se colocan en su domicilio... Sin embargo, el tono jocoso remata la ficción con la aparición de Saturno, literalmente «hecho el gracioso de esta farsa», quien pronuncia «no sin gracejo» (Sánchez de Oreja, [I742]: I5) —dice la narradora piscatora - una quintilla burlesca dedicada a una dama a la que pretendió, pero «al verla hora-dada», es decir, liviana, la despide con insultos:

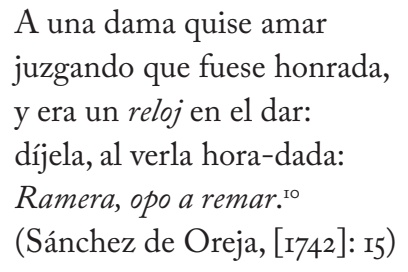

Con dobles sentidos y un palíndromo final muy contundente la voz autorial de doña Manuela parece querer afirmar su condición de dama, quizás para investirse de una autoridad moral con la cual pretendía apuntalar la literaria. A la vez, al poner en boca

Io Hay que entender opo con valor interjectivo, tal y como recogen los diccionarios académicos desde I9I4: ¡Hopo!: ‘'Largo de aquí! ¡Afuera!', a partir de la expresión seguir el hopo: 'que significa ir siguiendo y dando alcance a alguno' (DRAE, 1783 , en NTLLE). 
de Saturno esa alusión erótica tabernaria, enarbolaba su libertad creadora para practicar cualquier registro. A uno de los censores, José García Martínez, no le gustó mucho esa quintilla «diciendo con mil garatusas lo que ninguno penetra, ni ella entiende» (Sánchez de Oreja, [1742]: s. p.). Dentro del relato festivo habían quedado contrastados, hábilmente, las palabras de Saturno y el culto discurso de Venus, una diosa discreta que se sonrojaba con esos versos y que disimulaba antes de dictar el juicio del año a la narradora protagonista. Y se replanteaba ahí a escala mitológica la oposición comentada del prólogo: barbas-lampiñas, o autores-autoras; a la vez que se insistía en que el contraste masculinofemenino era también el de burlesco-serio, grosero-elegante, en elocuente connotación positiva de su sexo e implícita sátira masculina. La Gran Piscatora Aureliense concluía su «Juicio del año» con una nueva alabanza de sí misma, una octava entonada ahora por los coros planetarios que, al unísono, la colocaban sobre todos los astrólogos: «Adiós, ya lograste dichas, que nunca / astrólogo alguno pudo conseguir [...] / Inmortal tu fama logrará vivir» (Sánchez de Oreja, [1742]: 2I). Muy en serio.

Tal vez convencida de haber adquirido un lugar en la República de las Letras con esa obra y su eco favorable - lo denotarían las dos censuras emitidas, incluidas en la edición -, la segunda, Juicio y pronóstico del cometa... de I744, no incidía en el debate de los sexos. Tampoco ayudaba su corta extensión. Estructurado en tres partes, constituye una versión abreviada del almanaque habitual: introducción narrativa, un «Juicio del cometa» con información astronómica y un «Pronóstico del cometa» con predicciones judiciarias en verso. En la introducción, sin título, la autora se autorretrata como astróloga en su entorno local, capaz de proporcionar informaciones razonadas sobre el avistamiento excepcional de un cometa gracias a sus conocimientos y a los instrumentos de su observatorio astronómico. Todo se encamina a mostrar su prestigio científico, indiscutido e indiscutible, y ello a pesar de que su formación no incluyó el «compás» sino la «ilosa», un término que, como opuesto, apunta al ámbito doméstico:

Estupefactos quedaron mis consabidos compañeros; pero les aseguré que de todo cuanto les significa este catálogo lo mismo sabía yo antes que ahora, pues esto solo es para ciencias infusas y no para letrados que apenas se mueve el cierzo no salen de su cocina; y más yo, que antes me enseñaron la ilosa [sic] que el compás [...] (Sánchez de Oreja, [I744]: s. p.).

Se vislumbra ahí una doble ironía sobre sí misma, cuyos cálculos detallados fruto de su observación desmienten las «ciencias infusas» que menciona, y sobre esos letrados de salón, quienes, recluidos en «su cocina», ofrecen datos inexactos: otra antítesis pro domo sua, que invierte las argumentaciones misóginas. Con todo, el registro burlesco apenas se hace explícito en la predicción jocosa de una de las ocho décimas del pronóstico:

\footnotetext{
De algo habrá abundancia,

De otro algo escasez,

Entenderéislo al revés,

Y sacaréis la substancia:

Dice esta concordancia

Que el año será abundante

Por las lluvias de Levante,

Que dirán con mucha risa
} 


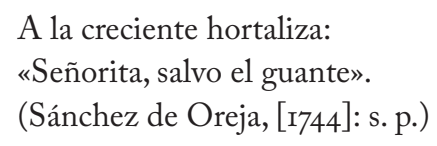

La siguiente almanaquera, Francisca de Osorio, mostraba de manera más evidente sus credenciales burlescas: tanto en el antetítulo de Pronóstico burlesco como en su festivo seudónimo, la Musaraña del Pindo, que convidaban a una lectura intrascendente y placentera. Sus prólogos, en esa línea, que era la de Torres, se valían de la ironía para apelar al lector: en los de 1756 y I757 — titulados «Prólogo al lector»e «Introducción», respectivamente- esgrime el motivo de la crítica por haber pagado, lo que la exime de tener que adularlo y de apreciar sus posibles cualidades, que agrupa en dos largas listas de opuestos: «Que para mí es lo mesmo. / Pues yo te he de querer mucho, / Como sueltes el dinero» (Osorio, I756: s. p.). El tercero es un prólogo «estrafalario» para el «lector científico", que adopta un enfoque metadiscursivo al proponer una serie de predicciones hipotéticas, algunas cómicas: «Si se confirman los éticos, / Si se bautizan los párvulos» (Osorio, I757: 2, vv. 27-28), «Si el que ayer era tomillo / Le verán mañana plátano», «Si a un sacristán melancólico / Se le comerán los tábanos», «Si robará el alguacil / Tanto como el boticario», «Si un extranjero aritmético / Se volverá sin aplausos» (ídem: 3, vv. 45-46, 53-54, 65-66), «Si vuelan en Estocolmo, / Como por acá los pájaros» (ídem: 3-4, vv. 69-70), «Si serán en Transilvania / Transparentes los carámbanos» (ídem: 4, vv. 83-84), etc.; tan larga es la serie que imagina a ese lector, en fin, colérico y cansado «Con tantos sies inútiles» y su estilo «jácaro» (ídem: 4, 6).

Sin embargo, ese tono jocoso alterna con un estilo conceptista aplicado a las protestas reivindicativas. Con ello Francisca de Osorio pretende afirmarse como escritora en femenino, $y$, significativamente, no reclama a sus lectores que ignoren la identidad sexual de quien escribe, como hacía su antecesora, sino que la tengan bien en cuenta. Aunque el fondo sea el mismo, porque la diferencia biológica presupone una indiscutible igualdad de capacidades, que es la que otorga el derecho de las mujeres a publicar. Las reivindicaciones progresan con cierta lógica siguiendo la serie que conforman los tres pronósticos. En el primero, al ser una autora novel, propone una adivinanza sobre su sexo, o la inevitable oposición hombre-mujer:

$$
\begin{aligned}
& \text { Si discurres que soy hombre, } \\
& \text { me obligas a contestar, } \\
& \text { que eres parecido a mí } \\
& \text { en eso del acertar. } \\
& \text { (Osorio, [1756]: s. p., vv. 39-42) }
\end{aligned}
$$

La respuesta errónea de que el autor es masculino, coherente con la estadística, la vincula a las mentirosas predicciones judiciarias. La correcta la convierte en afirmación arrogante de sí misma:

$$
\begin{aligned}
& \text { Si a que soy mujer te inclinas, } \\
& \text { (siendo esto la realidad) } \\
& \text { no tengo que agradecerte: } \\
& \text { lo dicho, dicho, y andar. } \\
& \text { (Osorio, [I756]: s. p., vv. 43-46) }
\end{aligned}
$$


El motivo de las mentiras se reformula unos versos después como reclamación de igualdad - lo mismo que la Gran Piscatora Aureliense-, de donde deriva un aval jocoso a su derecho a publicar pronósticos: «si es de veras, o de burlas, / el tiempo te lo dirá. / El tal sale de la imprenta / como todos los demás, / que mi Astrología sigue / en eso mucha igualdad» (Osorio, [I756]: s. p., vv. 51-56).

Seguramente, debieron de llegar a sus oídos comentarios sobre este pronóstico, porque en el del año siguiente doña Francisca se indigna de que se dude de su identidad femenina y de su capacidad como autora:

Mucho más pronosticara,

Si no me atajara el miedo,

Que me infunden los que dudan,

Si es que yo soy de mi sexo.

Astróloga el alma mía

Puede ser, ni más, ni menos,

Que la del hombre, aplicada

A esta ciencia, o embeleco.

(Osorio, 1756: s. p., vv. I37-I44)

Estos versos apuntarían a la existencia cierta de reticencias a las mujeres que publicaban, aunque la crítica haya constatado que, hasta la última década de Carlos III, hubo un «silencio discursivo sobre la escritora por parte de los hombres» (Sullivan, 2000: 316). Si Manuela Sánchez de Oreja las preveía antes de ver su letra impresa, Francisca de Osorio consigna las que sufrió de hecho. Y si en los versos anteriores practica de nuevo la broma sobre la fiabilidad astrológica, no la hay en la reclamación de su capacidad como autora. De este modo, va configurando una imagen de mujer fuerte, aunque en paralelo ofrezca un autorretrato burlesco que mitiga la firmeza expresada con algunos tópicos humorísticos del campo adivinatorio: «Que metafísica estoy / Tan espiritual, y sin cuerpo / Que bien puedo aparecerme / A la Beata de Marcelo» (Osorio, I756: s. p., vv. 63-66). El estilo argumentativo y tono grave reaparecen luego, esta vez para esgrimir pruebas no ya de igualdad sino de superioridad femenina en dos sentidos: por su situación postergada son más cautelosas; y aunque las capacidades no estén vinculadas a los sexos, los textos escritos o por escribir de tantas escritoras son mejores que los de muchos escritores publicados:

No está el saber vinculado

En los años y en los sexos,

Que a estarlo, sin duda fueran

Los más sabios los más viejos,

Ignorante toda hembra

$Y$ todo varón discreto.

Ellas escriben también,

Y mejor que muchos de ellos;

Y otras, que no escriben, sé

Que pueden dar documentos

A tantos que dan a luz

La obscuridad de su ingenio.

(Osorio, 1756: s. p., vv. I49-160). 
De lo general de este planteamiento pasa al final a proclamar el suyo en primera persona:

$$
\begin{aligned}
& \text { Yo no me valgo de nadie, } \\
& \text { Mendigando entendimiento, } \\
& \text { Que para estos disparates } \\
& \text { Me basta el poco que tengo. } \\
& \text { Quiera Dios que nos veamos } \\
& \text { Yo contenta y tú contento } \\
& \text { Con la Musa y con la mosca, } \\
& \text { pues de este modo remedio } \\
& \text { De la estrella, que me sigue, } \\
& \text { El traidor influjo adverso [...] } \\
& \text { (Osorio, I756: s. p., vv. I6I-I7o) }
\end{aligned}
$$

Medio en broma, medio en serio. Si el género consiste en «disparates», tópico y evidencia, que ella lo practique es la única vía al alcance para hacer realidad su inevitable «estrella» o vocación literaria, convencida de su capacidad para abordar géneros mayores. Se observa aquí que a las trabas que el mercado ponía a las escritoras, que ya había denunciado Manuela Sánchez de Oreja, se sumaba la específica de poder publicar «obras de mayor enjundia» (López-Cordón, 2006: 200).

La afirmación de sí misma se consuma en el tercer pronóstico de esta piscatora, entre el prólogo o «Introducción» y el «Juicio del año», ahora con mayor número de versos y más complejidad retórica, en un vaivén continuo entre lo serio y lo humorístico. Su presentación al lector como «Mujer astróloga» parece una culminación de las argumentaciones anteriores, una significativa redundancia que apostilla «aunque parece milagro» (Osorio, I757: I, vv. 3-4), consciente de la coyuntura adversa. Enseguida, continúa su autorretrato en clave paródica con referentes literarios esotéricos habituales en el género: es una «sabandija» que tiene por sesos «trasgos» y que escribe «discursos frenéticos» (vv. 5-7), que concreta más adelante con una lista de supuestas predicciones, jocosas la mayoría, tras las que ofrece un retrato fantasmal burlesco: «Mi semblante cadavérico / Hace volar los galápagos» (Osorio, I757: 5, vv. IIO-III). Ya en el juicio anual a continuación el tono se hace insolente, descarado, y el retrato, esta vez de su yo autorial, se impone sobre las predicciones esperables, extendido en 92 versos de los I 40 totales. Todo parece, pues, al servicio de una presentación reivindicativa, que comienza ironizando:

$$
\begin{aligned}
& \text { Vaya de Juicio, Señores, } \\
& \text { De Juicio del año vaya, } \\
& \text { Que ha de ser juicio de juicios } \\
& \text { El juicio que aquí se haga. } \\
& \text { Nadie da lo que no tiene, } \\
& \text { Dicen, que es basa sentada: } \\
& \text { Yo doy juicio y no le tengo } \\
& \text { (Osorio, } 1757: 9 \text {, vv. I-7) }
\end{aligned}
$$

El juego de palabras parte del significado literario de «juicio» para incidir en el campo semántico de la locura. Una vez ahí, en una especie de gradación, la persona narradora va aclarando el término: «loca singular» o genial (v. I5) y «varia» (v. 26), es decir, diversa 
o compleja; $;$ "II para proclamar después su independencia autorial sobre las conjeturas propagadas de que le influye algún hombre, «abogado» o «sotana»; y, en fin, su capacidad para «Poner tantos silogismos / Como se oyen en las aulas / Y probarlos fácilmente» (vv. 32-34). La variada lista de saberes que detalla - los he mencionado al principio (vv. 37-68) - lo corrobora. Tanta afirmación arrogante concluye con otro juego de palabras metadiscursivo:

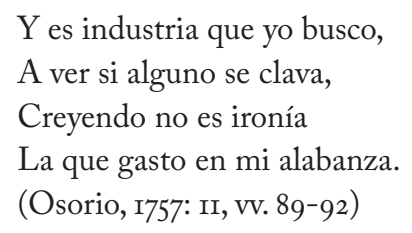

Ironizar sirve para matizar, para matizarse, pero como es parte de la burla intrínseca al género, en realidad muestra a una hábil narradora bastante segura de sí misma y, por ende, a la ingeniosa autora. Si su predecesora la Gran Piscatora Aureliense hacía a Venus portavoz de sus capacidades superiores a los demás astrólogos dentro de un juego literario, ella, la Musaraña del Pindo, ha ido construyendo su imagen progresivamente con cada Pronóstico burlesco, con argumentos serios mezclados con elementos acordes a ese calificativo. Comienza de modo tópico en su primer prólogo en 1756 como la «Musa bozal» o necia del Grande Torres (Osorio, [I756]: s. p., v. Io8) y musa «Moderna y tonta» en el poema que glosaba la luna nueva de diciembre de ese año, ${ }^{\mathrm{I2}} \mathrm{y}$ acaba definiéndose con un pleonasmo como mujer astróloga. Antes ha rechazado el connotado grado de Bachillera en «tan profundas materias» para el juicio de $\mathrm{I} 757$ (Osorio, I756: 4).

En fin, los textos citados y comentados pueden dar buena muestra del estilo de estas dos autoras, basado en un contraste de tonos, entre lo jocoso del género y la afirmación en serio de sí mismas, que evita caer en lo que Durán (2015:47) denomina «estilo perdulario» de Torres, y que derivaba a lo bajo en las ficciones literarias de muchos almanaqueros. Las almanaqueras no solo eran cultas, sino que debían parecerlo, de ahí que su exhibición literaria esté dominada por el buen gusto y el ropaje clásico o el juego conceptista de ingenio. Lo hemos visto: tras unas dedicatorias tópicas, los prólogos se cargan de reivindicaciones, combinadas con motivos del género adivinatorio. Luego, la introducción literaria de la Gran Piscatora Aureliense discurre por refinados espacios mitológicos, presididos por Venus, en vez de las cuevas lóbregas o los espacios cotidianos de entremés de sus compañeros almanaqueros. Y la Musaraña del Pindo, que adopta el verso desde la misma dedicatoria, despliega en sus juicios del año tan literarios - el segundo incluye una ficción mitológica - su capacidad para la argumentación y la versificación.

A pesar de las críticas que temieron o constataron, ambas escritoras fueron apreciadas por su ingenio, como prueba de su facultad creadora en general sino como una concreta aptitud para lo gracioso. El trinitario calzado Fray Diego de la Cruz, primer censor de Sánchez de Oreja, la ensalzaba igualándola: «el ingenio y la discreción no está ligada solo a el sexo varonil, si no es que quieran llamar varonil al ingenio», aplaudiendo a «el autor, en que para diversión escoja tal Facultad» (Sánchez de Oreja, [1742]: s. p.). Y al segundo censor, el Dr. Joseph García Martínez, párroco en la Corte, poco amigo de los pronósticos judiciarios por «agoreros», le tranquilizaba la clave burlesca que ella confesaba: «quiere

II El Diccionario de Autoridades define vario como 'Diverso, ò diferente' y 'lo que tiene variedad, ò está compuesto de diversas formas' (RAE, I739, en NTLLE).

I2 Se trata de dos versos: «Es esta historia, / Y la Musa que escribe, /Moderna y tonta» (Osorio, [I756]: 38). 
nuestra fortuna que protestando en su prólogo las mentiras de los otros, incluye en ellas las suyas, que, en poco, o solo en el modo, se diferencian, pues ni nos pronostica ni más alegre, ni menos triste» (ídem).

Las reacciones a Francisca de Osorio las formularon sus propios amigos, a quienes había convocado para escribirle poemas laudatorios, que insertó al principio de cada almanaque, según se acostumbraba en los géneros canónicos serios. En el primero de ellos, Matías Joseph Sanz se suma al tono festivo con un extenso romance, en que, lanzado por la Fortuna «desde la cumbre del Pindo / hasta la sima de Cabra», recreaba una escena narrativa donde él y «ciertos camaradas» examinaban el pronóstico en cuestión con imágenes culinarias; y considerándolo digno de imprimirse, él mismo acababa apostrofando a la autora, tras ofrecer «mi voluntad a tus plantas, / vive los años del Fénix, / por ver si te nacen Barbas» (Osorio, [1756]: s. p.). Cortesía y broma en masculino, para incorporar a ese terreno el raro ingenio de la escritora. En el tercer pronóstico la alabanza se componía de tres décimas escritas por un anónimo «apasionado a la autora», la última de las cuales establecía un diálogo intertextual con el comienzo del «Juicio del año», antes comentado:

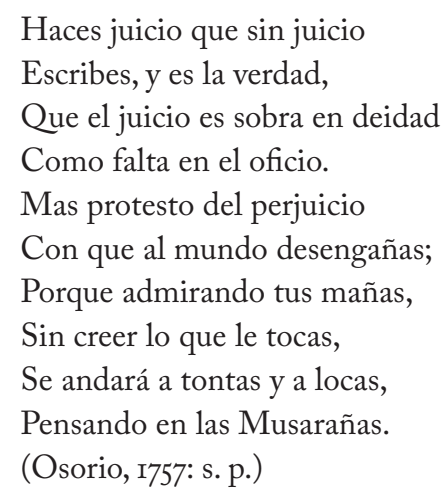

Tal vez falta de más amigos que le escribieran, fue este un poema de propia mano, un comentario a la manera cervantina a su propia confesión de que escribía un juicio sin tenerlo, lo que incitaba a no leerla en serio. Confesando el carácter burlesco de lo que escribe, el lector admirará sus «mañas», su ingenio, y se quedará pensando en ella como escritora, la Musaraña, autora no de predicciones sino de un texto literario.

Estos versos son un buen ejemplo del nuevo uso en clave femenina que las piscatoras confieren al pronóstico burlesco torresiano, convertido en un ejercicio con que reclaman su condición autorial a la vez que demuestran sus capacidades literarias. Si en el plano del contenido añaden al género adivinatorio el plus temático reivindicativo, ausente por innecesario en sus colegas masculinos, en el plano formal adoptan la burla, un elemento retórico intrínseco, de modo que resulta una hábil manera de introducir las reivindicaciones más firmes. La burla, pues, se pone al servicio de una literatura apologética de su sexo, característica de la producción dieciochesca femenina (García Garrosa, 2007: 208). Su formulación por las autoras analizadas comparte los siguientes rasgos:

- Lo burlesco se combina con el tono serio de las afirmaciones de "género", que se presentan como antítesis entre femenino-masculino.

- Utiliza los lugares comunes torresianos - mentiras judiciarias, lector que paga-y los recursos estilísticos habituales —ironía, juegos de palabras, comparaciones...- para desarmar la supuesta inferioridad de las mujeres escritoras.

- Se evitan las chabacanerías o elementos grotescos, ya que son damas y aspiran a ser tomadas como escritoras serias y profesionales. 
Cada una con su idiosincrasia literaria y personal dota al arma del humor de una nueva funcionalidad: no ya la de mitigar las consabidas críticas a la futilidad o a la invalidez de los pronósticos judiciarios, sino la de revertir los recelos a la incursión femenina en el ámbito público de la escritura. Las afirmaciones explícitas jocoserias quedan reforzadas con la cultura que exhiben, con sus habilidades literarias y con el pronóstico mismo. No importaría demasiado que los archivos pudiesen descubrir tras los nombres de estas dos autoras un caso de «travestismo» literario - los hubo en la época-, porque lo relevante es la identidad autorial femenina que construyen y desde la que ambas realizan su peculiar planteamiento apologético para intervenir en el debate dieciochesco sobre las capacidades de la mujer, continuando la temprana defensa de Feijoo. Y lo hacen ya en los años 40 y 50, anticipándose a lo expresado en el periódico La Pensadora Gaditana (1763I764), ${ }^{13}$ a la polémica de la admisión de mujeres en la Real Sociedad Matritense en los 80 y a los escritos reivindicativos en la última década del siglo de Josefa Amar y Borbón e Inés Joyes. ${ }^{14}$ A Manuela Sánchez de Oreja y a Francisca de Osorio, matemáticas y literatas, el molde de los pronósticos torresianos, con la retórica que comportaba, entre burlas y veras, les permitió adentrarse en la masculina República de las Letras, aunque fuese de forma efímera.

\section{BibLiografía}

Aguilar Piñal, Francisco (1981-200I), Bibliografía de autores españoles del siglo XVIII, io vols., Madrid, CSIC.

Álvarez Barrientos, Joaquín (2006), Los hombres de letras en la España del siglo XVIII. Apóstoles y arribistas, Madrid, Castalia.

Amar y Borbón, Josefa (1994), Discurso sobre la educación física y moral de las mujeres, María Victoria López-Cordón (ed.), Madrid, Cátedra.

BIESES [en línea], Bibliografía de escritoras españolas, https://www.bieses.net.

Bolufer Peruga, Mónica (2006), «Transformaciones culturales. Luces y sombras», en Isabel Morant (dir.), Historia de las mujeres en España y América Latina. Vol. II. El mundo moderno, Madrid, Cátedra, $2^{\mathrm{a}}$ ed.

- (2008), La vida y la escritura en el siglo XVIII. Inés Joyes: Apología de las mujeres, Valencia, Universitat de València.

Canterla, Cinta (2018), «Beatriz Manrique de Lara Alberro, marquesa de García del Postigo, autora de La Pensadora Gaditana bajo el pseudónimo de Beatriz Cienfuegos», Cuadernos de Ilustración y Romanticismo, $\mathrm{n}^{\circ}$ 24, pp. 741-755.

Durán López, Fernando (2015), Juicio y chirinola de los astros. Panorama literario de los almanaques y pronósticos astrológicos españoles (I700-I767), Gijón, Ediciones Trea.

- (2013), «Primer teatro de almanaques españoles. (La Gran Piscatora Aureliense para 1742, pepitoria de 1745 y palinodia burlesca en verso de Gómez Arias para 1754)», Cuadernos de Ilustración y Romanticismo, $\mathrm{n}^{\circ}$ 19, pp. 403-457.

I3 Véanse Romero (1994) y la selección editada por Canterla (1996), quien recientemente (2018) ha documentado la identidad de la autora oculta bajo el seudónimo con que apareció.

I4 El debate en la Matritense, iniciado en 1786 tras la admisión excepcional de dos socias, María Isidra de Guzmán y la condesa de Benavente, ha merecido bastante atención de la crítica. Véanse Bolufer (2006: 502-506) y las memorias de los intervinientes, editadas por Negrín (I984: I3I-I83), que también comenta el debate. En él intervino Amar y Borbón con el Discurso en defensa del talento de las mujeres y de su aptitud para el gobierno y otros cargos en que se emplean los hombres (I786), ideas que continuó con el Discurso sobre la educación física y moral de las mujeres (I790) —editado por López-Cordón (1994)—. Inés Joyes insertó una encendida Apología de las mujeres como apéndice a su traducción de El principe de Abisinia, novela de Samuel Johnson (Madrid, Sancha, I798), editada y comentada modernamente por Bolufer (2008). 
García Garrosa, María Jesús (2007), «La creación literaria femenina en España en el siglo xviII: un estado de la cuestión», Cuadernos de Historia Moderna. Anejos, no vi, pp. 203-219.

GonzÁlez, Teresa (I778), El estado del cielo para el año de I778, arreglado al meridiano de Madrid..., por La Pensadora del Cielo, doña..., Madrid, En la Imprenta y Librería de D. Manuel Martín.

La pensadora gaditana, por Doña Beatriz Cienfuegos (1996), Cinta Canterla (ed.), Cádiz, Servicio de Publicaciones de la Universidad.

López-Cordón, María Victoria (2006), «La fortuna de escribir: escritoras de los siglos xvir y XVIII», en Isabel Morant (dir.), Historia de las mujeres en España y América Latina. Vol. II. El mundo moderno, Madrid, Cátedra, pp. 193-234.

Negrín, Olegario (I984), Ilustración y educación. La Sociedad Económica Matritense, Madrid, Editora Nacional.

Osorio Guzmán, Francisca de ([I756]), Prognóstico burlesco de La Musaraña de Pindo, su autora Doña..., para el año de 1756, En Madrid, en la Imprenta de Antonio Marín.

(I756), La Musaraña del Pindo, Pronóstico burlesco para el año de I757. Su autora Doña..., En Madrid, En la Oficina de D. Gabriel Ramírez.

- (1757), La Musaraña del Pindo, Pronóstico burlesco para el año de I758. Su autora Doña..., En Madrid, En la Oficina de D. Gabriel Ramírez.

Palacios Fernández, Emilio (2OI2), «Bibliografía general de escritoras españolas del siglo XviII», nueva versión en Bibliografía de Escritoras Españolas (BIESES), https://www.bieses.net/ emilio-palacios-fernandez/.

Real Academia Española, Banco de datos (CORDE) [en línea], Corpus diacrónico del español, http://www.rae.es.

- Nuevo tesoro lexicográfico de la lengua española (NTLLE), http://buscon.rae.es/ntlle/ SrvltGUISalirNtlle.

Romero, María (1994), «Una primera visión de cambio en la mujer del s. Xvili, bajo los "Pensamientos" de Beatriz Cienfuegos», en La pensadora gaditana, en Cinta Canterla (ed.), VII Encuentro de la Ilustración al Romanticismo. Cádiz, América y Europa ante la modernidad. La mujer en los siglos XVIII y XIX, Cádiz, Servicio de Publicaciones de la Universidad, pp. 609-6ig.

Sánchez de Oreja, Manuela Tomasa ([1742]), La Gran Piscatora Aureliense en el teatro de signos y planetas. Pronóstico y diario general de cuartos de luna, juicio de los acontecimientos naturales y políticos de la Europa y otras partes; para el año de I742, En Madrid, por los Herederos de la Viuda de Juan García Infanzón.

- Nicolasa ([I744]), Juicio y pronóstico del cometa, que se dejó ver sobre nuestro hemisferio el día $I_{2}^{\circ}$ del mes de enero de este año de I744, por Doña..., s.1., s. n.

Serrano Sanz, Manuel (1975), Apuntes para una biblioteca de escritoras españolas desde el año I4OI al I833, Madrid, Atlas, t. I y II.

Sullivan, Constance A. (2000), «Las escritoras del siglo xviıı, en Iris M. Zavala (coord.), Breve bistoria feminista de la literatura española (en lengua castellana). Vol. IV. La literatura escrita por mujer. De la Edad Media al siglo XVIII, Madrid, Anthropos / Universidad de Puerto Rico. 


\section{ApÉNDICE}

Juicio y pronóstico del cometa que se dejó ver sobre nuestro hemisferio el día I2 del mes de enero de este año de I744. ${ }^{I 5}$ Por doña Nicolasa Sánchez de Oreja, profesora de Matemáticas en el partido de la villa de Ocaña

Tristemente dolorida y cansada de aguantar tanto tiempo una impertinente llaga, que me amaneció en un muslo el día 29 de septiembre del año pasado de 1743 , y con la sobrecarga de un resfriado bastante entremetido, me hallaba el día I2 de enero de este de I744 en mi cama, a las 7 y 36 minutos de la tarde, cuando entraron en mi cuarto innumerables gentes de todas clases, sexos y edades, gritando con voces lánguidas y desconcertados acentos, pidiéndome que por amor de Dios les sacase del pasmo y susto que les agitaba un caperucho de color ígneo flamante y de extraordinario grandor, que registraban en el cielo. ${ }^{16}$

Oí su pregunta, no dejándome de admirar de la repentina novedad; pero deseando más mi recogimiento que seguir los sustos y sofísticos arambeles del vulgo, me sosegué un poco y supliqué a aquel curioso tumulto se fuese con Dios, que al día siguiente examinaría mis fuerzas y procuraría consolar su desconsuelo, pues no era razón me hiciesen levantar a tan extraordinaria hora sin hacerse cargo de mis achaques. Pero aún no fue oída esta disculpa cuando, con nuevas y más vivas instancias me pidió su curiosidad dejase la cama y fuese a ver, discernir y calcular qué resplandor y qué efectos podía causar. Entonces yo, como enfadada, picada de valiente, y como que mi curiosidad me hacía cosquillas (ordinario aforro de todas las mujeres), les ofrecí levantarme, y tal cual sacarles del susto que les causaba tan extraordinaria visión. Alegráronse mucho, me dieron las gracias, y con mucha puntualidad me ayudaron a vestir. En fin, salí de mi alcoba, acompañada de la numerosa procesión y desarreglado concurso, tan atento a mis pláticas que, si por ventura hablaban entre sí, apenas tosía o bostezaba yo, cuando callaban como mármoles, juzgando que el más leve estornudo era la más clara disparidad o explicación de su temido fantasma.

De esta manera llegamos a una azotea, donde tengo una tertulia o garita de tablas de Zarcedilla ${ }^{17}$ con todos mis astronómicos instrumentos, que no los había visto desde el año pasado de $\mathrm{I}_{742}$, en que escribí el pronóstico que con mi nombre, apellido, profesión y patria salió a luz en la siempre coronada villa de Madrid, y aquel populacho me hizo la honra de registrarle, y lo dediqué al insigne astrólogo y catedrático de Matemáticas en Salamanca, el señor don Diego de Torres y Villarroel, mi siempre fiel y apasionado correspondiente. Puesta ya, como he dicho, en el descubierto teatro de mi azotea, volví los ojos al cielo, y registré sobre una estrella un grande escobón, que unos suelen llamar fenómeno y otros cometa, y deseando complacer a mis asustados compañeros, ofrecí les daría parte de mis escrutinios, tomando el trabajo de registrar algunas noches (como lo hice las de los días I3, I6, I9 y 20 del citado enero, salvando los días en que las nubes no me lo permitían ver) aquella extraordinaria lucerna, y decirles por escrito lo que era y los efectos que podría causar, arreglándome a los libros, a la experiencia y a los callos que en mí ha fraguado la afición de semejantes tareas, y me pareció poner el juicio en prosa y el

I5 Modernizo la ortografía y puntuación originales, igual que en las anteriores citas textuales.

I6 Se trata del Gran Cometa de I744, uno de los más espectaculares observados, llamado de Chéseaux-Klinkenberg a partir de dos de los astrólogos que lo descubrieron, de forma separada: el primero en Lausana y Klinkenberg en Haarlem en diciembre de $\mathrm{I} 743$. Al principio constaba de seis colas, que fueron juntándose hasta dos en febrero, y una sola tras su perihelio, alcanzado el i de marzo de I744.

I7 Zarcedilla: parece aludir a una madera relacionada con un topónimo, tal vez deformación o variante de «Cercedilla», localidad de la sierra madrileña rica en bosques. 
pronóstico en verso. Agradóles mi respuesta, y reiterándome el cuidado, ofreciéndome seguro agradecimiento, se despidieron de mí, que solo quedé acompañada de un perrito chino y un gato maltés, que siendo uno el símbolo de la lealtad y el otro de la ingratitud, me acompañan continuamente, dando muestras contrarias a las que se pueden esperar de tan extravagante mixto.

Obligada ya a discernir la genealogía de la pasmosa visión, y en cumplimiento de lo que tengo ofrecido, diré lo que se me alcanza, aunque confieso que las criaturas, sin especial gracia del Todopoderoso, no pueden asegurar sus influjos; y pues solo se dirige mi intención a satisfacer mi palabra, los que leyesen este rescripto crean lo que les parezca, que yo no me he de enojar por ello.

\section{Juicio del cometa}

Según el sentir de mis compatriotas, este cometa (que así se debe llamar contra el sentir de algunos que defienden ser lo mismo cometa que fenómeno), el día I2 de enero de este año de 1744 y según mi estudiosa reflexión, estaba sobre el signo de Aries y en el mismo cielo de la Luna.

La primera noche de mi cuidado me pareció que la cola del cometa o coroza de fuego subía rectamente; pero habiéndolo observado cuatro días más como dejo dicho, pude conocer que se declinaba hacia el Oriente el remate del penacho; y esto mismo se me avisa de Cádiz, Barcelona y Alicante. Su grandeza o longitud alcanzaría hasta 27 grados celestes, que regulados hacen 486 leguas. Esto tendría las noches de los días I2, I3, I6 y I9, pero la noche del día 20 le registré de alcance más de 500 leguas; y no siempre le he visto de una misma forma, pues el día I2 apareció con el color más encendido que los días I3 y 19. El día r6 se dejó ver con el color más blanco, y el día 20 y último de mi observación algo más obscuro; pero nunca se le descubrió el color denso, encarnado ni ceniciento como en otros cometas se ha visto varias veces.

Sobre la materia de que se forman los cometas hay variedad de opiniones. Unos dicen formarse de espumas salitrosas del mar; otros, de átomos nitrosos de la Tierra; y otros, de aires infectos y corrompidos; discursos que en mi sentir más visos tienen de majaderas salvajadas que de trabajos estudiosos. Yo me atreveré a asegurar que el presente cometa se ha formado de diferentes partículas solares; pues no es creíble ni puede ser que cosa huela a terrestre pueda elevarse hasta el cielo de la Luna, donde se registra este cometa, por los escollos en que les sería preciso zozobrar y reducirse a la misma nada; o bien sea por la región del fuego o por la soberana influencia del Lucero mayor; y lo mismo le sucedería al mayor peñasco del mundo si dable fuera poderse elevar.

Yo, creyendo como cristiana que Dios nuestro Señor mueve los astros y demás criaturas, creo que este cometa se nos ha venido a la vista por especial providencia suya y para manifestar lo enojado que le tienen nuestras culpas, privándonos la comprehensión de los soberanos arcanos que puede influir este u otro cometa; pero, no obstante, daré mi sentir en los versos del siguiente pronóstico, asegurando al que lo leyere que digo lo que no alcanzo, dejándole la libertad de que crea lo que le parezca. 
Un cometa, bien mirado, Según buena Astronomía, Jamás de alguna alegría La menor señal ha dado: Y así, pues se ha notado Que desdichas nos ofrece, $\mathrm{Y}$ aunque a todos nos parece, Que ya no hay más que llorar, Dios nos quiera consolar, Más que al Demonio la peste.

Este cometa, señores, Por ser todo celestial En vez de anunciarnos mal, Nos asegura favores: Mírense sus resplandores, $\mathrm{Y}$ con buena inteligencia Se verá que su influencia Solo se deja palpar Del que le pudo criar Con su suma omnipotencia.

Peste no hay que temblar, Guerras no hay que temer, Que la paz ha de vencer, Y todo se ha de acabar: Ruede, pues, y sin parar La fortuna en su dechado, Que al infeliz desdichado Que no amará a su Señor Será, sobre su dolor, Cornudo y apaleado.

A un soldado que usurpó Del príncipe a quien servía La corona que tenía, La muerte le amenazó: Por entonces no murió, Pero se verá afligido, $\mathrm{Y}$ en suma tan perseguido Que se llegará a valer De quien le supo vencer, Aunque nunca fue vencido.
En una bella ciudad

Que Leo la predomina Habrá muy grande ruina, Nacida de sequedad: $\mathrm{Y}$ en esta conformidad, El mismo signo es señor De provincias un horror, Y de una de ellas saldrán Diversas gentes, que irán Las jornadas del calor.

Una posta ha de salir, Y aquel que la correrá El galardón llevará

Con acabar de vivir:

$\mathrm{O}$ qué ganas de reír Le darán a un veterano Que no cree que una mano Que jamás de él fue temida Le podrá quitar la vida Como al mejor ciudadano.

De algo habrá abundancia, De otro algo escasez, Entenderéislo al revés, Y sacaréis la substancia: Dice esta concordancia Que el año será abundante Por las lluvias de Levante, Que dirán con mucha risa A la creciente hortaliza: «Señorita, salvo el guante».

A un presumido letrado Borrasca le correrá, Y su golilla será El plato de un convidado: Caerá precipitado Un valiente espadachín, Y quedará su rocín En tan grande confusión Como peras de montón Y alaridos de motín. 
Estupefactos quedaron mis consabidos compañeros; pero les aseguré que de todo cuanto les significa este catálogo lo mismo sabía yo antes que ahora, pues esto solo es para ciencias infusas y no para letrados que apenas se mueve el cierzo no salen de su cocina; y más yo, que antes me enseñaron la ilosa $[\text { sic }]^{18}$ que el compás; y así suplico a Vds. se sirvan admitir este papel en cumplimiento de mi promesa, haciéndome al agasajo de perdonarme y mirar con atención este último rengloncillo del DIOS SOBRE TODO.

I8 ilosa, tal vez por filosa: «ido en habito de fembra et filando purpura en vna filosa o rueca» "**k 1376 -I396, Fernández de Heredia, Juan, Traducción de la Historia contra paganos, de Orosio, Valencia, Pontificia (Juan Manuel Cacho Blecua, Universidad de Zaragoza (Zaragoza), 2003). «Et trobolo entre muchas fembras filando seda con filosa» ***385, Fernández de Heredia, Juan, Gran crónica de España, I. Ms. IoI33 BNM. (Real Academia Española: Banco de datos (CORDE) [en línea]. Corpus diacrónico del español. <http://www.rae.es>). El Diccionario de Autoridades y los académicos recogen filosa como sinónimo en germanía de espada, pero solo Terreros indica en esta voz la acepción textil: 'En las fábricas de paños, tabla que asegura la canal, y sobrecanal' (RAE, I798, en NTLLE). No he podido documentar ilosa ni bilosa. 